\title{
Numerical Study of the Greenhouse Effect in a Flat-plate Double Glazing Solar Heat Collector
}

\author{
Tene Hedje Patrick1, Tetang Fokone Abraham ${ }^{1,}{ }^{*}$, Edoun Marcel1,2, Kuitche Alexis ${ }^{1}$ \\ ${ }^{1}$ Laboratory of Energetic and Applied Thermic (LETA), National School of Agro-Industrial Sciences (ENSAI), The \\ University of Ngaoundere, B.O. 455, Ngaoundere, Cameroon; abramtetang@yahoo.fr \\ 2Department of Electrical Engineering, University Institute of Technology of Ngaoundere, \\ Cameroon. Tel: (+237) 675095065.
}

\begin{abstract}
Objectives: The work presented concerns the modelling of the greenhouse effect in a double-glazed flat-air solar thermal collector. Methods/analysis: A mathematical model was used to determine the net infrared radiation absorbed as well as the radiation losses at the absorber level by considering all the possible radiation paths within the collector. For the computation, a parametric study of the collector and a theoretical characterization in natural sunshine in the city of Ngaoundere for the month of April were carried out. Findings: The results show that, when the collector is facing south and inclined at an angle of $30^{\circ}$ to the horizontal, the solar noon is reached at $12: 30 \mathrm{pm}$ and at this time; the maximum temperature of the absorber is $88{ }^{\circ} \mathrm{C}$ for maximum sunshine of $1032.59 \mathrm{~W} / \mathrm{m}^{2}$. The declination in this locality ranges from $2.98^{\circ}$ to $13.69^{\circ}$ during the month of April. Analysis of the Infrared radiation profile reveals that the net IR radiation absorbed is $678 \mathrm{~W} / \mathrm{m}^{2}$ with IR radiation losses to the absorber estimated at $250 \mathrm{~W} / \mathrm{m}^{2}$. Application/improvement: The greenhouse effect is used for the optimization of heat transfer through solar collectors and greenhouses for drying.
\end{abstract}

Keywords: Solar Collector, Double Glazing, Declination, Infrared Radiation, Greenhouse Effect

\section{Nomenclature}

\begin{tabular}{|l|l|l|}
\hline $\mathbf{S}_{\mathbf{f}}$ & Passage section of the moving fluid & {$\left[\mathrm{m}^{2}\right]$} \\
\hline $\mathbf{H}_{\mathbf{h}}$ & hydraulic height & {$[\mathrm{m}]$} \\
\hline $\mathbf{D}_{\mathbf{h}}$ & $\begin{array}{l}\text { hydraulic diameter equivalent of the } \\
\text { useful duct }\end{array}$ & {$[\mathrm{m}]$} \\
\hline $\boldsymbol{C}_{\boldsymbol{p}}$ & Specific heat of the air & {$[\mathrm{J} / \mathrm{kg} \mathrm{C}]$} \\
\hline $\boldsymbol{n}$ & air mass flow & {$[\mathrm{kg} / \mathrm{s}]$} \\
\hline $\boldsymbol{L}$ & Characteristic length of the collector & {$[\mathrm{m}]$} \\
\hline $\boldsymbol{l}$ & Characteristic width of the collector & {$[\mathrm{m}]$} \\
\hline $\boldsymbol{T}$ & Temperature & {$\left[{ }^{\circ} \mathrm{C}\right]$} \\
\hline $\mathbf{h}$ & Transfer coefficients & {$\left[\mathrm{W} / \mathrm{m}^{2} \mathrm{~K}\right]$} \\
\hline $\mathbf{U}_{\mathbf{b}}$ & $\begin{array}{l}\text { Loss coefficient to the rear of the } \\
\text { collector }\end{array}$ & {$\left[\mathrm{W} / \mathrm{m}^{2} \mathrm{~K}\right]$} \\
\hline
\end{tabular}

\begin{tabular}{|c|c|c|}
\hline \multicolumn{3}{|c|}{ Dimensionless Number } \\
\hline $\boldsymbol{R}_{e}$ & Reynolds Number & \\
\hline$P_{r}$ & Prandtl Number & \\
\hline$R_{a}$ & Rayleigh Number & \\
\hline \multicolumn{3}{|c|}{ Greek symbols } \\
\hline$\mu$ & Dynamic viscosity of the medium & {$[\mathrm{Pa} . \mathrm{s}]$} \\
\hline$\lambda$ & Thermal conductivity & {$\left[\mathrm{W} / \mathrm{m}^{\circ} \mathrm{C}\right]$} \\
\hline$\varphi$ & $\begin{array}{l}\text { Angle of the collector relative to the } \\
\text { horizontal }\end{array}$ & {$\left[{ }^{\circ}\right]$} \\
\hline$\sigma$ & Stephan-Boltzmann's constant & \\
\hline$\varepsilon$ & Emissivity & \\
\hline$\tau$ & Transmission coefficient & \\
\hline$\alpha$ & Absorption coefficient & \\
\hline$\rho$ & reflexion coefficient & \\
\hline
\end{tabular}




\begin{tabular}{|c|c|c|c|}
\hline \multicolumn{4}{|c|}{ Index } \\
\hline$a m b$ & Ambient & $s$ & Outlet \\
\hline$c$ & transparent cover & is & $\begin{array}{l}\text { Insulating } \\
\text { materials }\end{array}$ \\
\hline$a b$ & Absorber & $c v$ & Convection \\
\hline$f$ & Fluid & $r$ & Radiation \\
\hline$e$ & Inlet & & \\
\hline
\end{tabular}

\section{AQ3 1. Introduction}

Solar Energy is considered the oldest energy in the world and on which almost all other energy sources depend. 1 It is used either directly or after transformation into other forms of energy (thermal energy, electrical energy).

The central element of applications using the thermal energy of the sun is the thermal solar collector. It converts the radiant energy of the sun into thermal energy extracted by the flowing fluid. This energy is used in various applications such as drying, domestic and industrial heating, solar cold production, etc.

Most of the research is devoted to the development of the solar collectors using water as heat transfer fluid in terms of thermal efficiency in general, there are few studies on solar collectors using air as heat transfer fluid because, air does not have a better heat exchange efficiency due to its low thermo-physical properties. 2 However, with the current technological development, this field has undergone significant renewal in theory and experiment. $\underline{\underline{2}-\underline{8}}$ Thus, several scientific studies have been carried out on these collectors, with the aim of optimizing the useful energy transmitted to air, by acting on the optical (relating to transparent covers) and geometric (shapes and dimensions) properties of the collector, as well as all other parameters that may affect its thermal performance. $\underline{\underline{9}} \underline{\underline{13}}$

Transparent cover in a collector has the dual function of allowing the maximum amount of solar radiation to pass and avoiding the cooling of the absorber, reducing air convection phenomena and "blocking" infrared radiation emitted. $. \underline{14}, \underline{15}$ Such a device, therefore represents a real trap for solar radiation, which can be improved by providing the collector with a double cover. It then realizes the greenhouse effect, which involves both solar radiation and infrared radiation.

Important studies have been carried out as part of the optimization of flat-air solar collectors. $\frac{16,17}{1 n}$ particular, there is an important bibliography on the exchange modelling in collectors $\underline{6}, \underline{18}-\underline{22}$ but until now, it has only been concerned with macroscopic phenomena, the influence of Infrared radiation (greenhouse effect) has always been mentioned superficially. Although mathematical modelling of infrared thermal radiation within the greenhouse has been developed, $\underline{2,}, \underline{24}$ such work with respect to solar air collectors is quite rare. In this paper, a modelling of the greenhouse effect in the doubleglazed flat-plate collector is presented.

\section{Modeling exchanges}

The flat-air solar thermal collector which is the subject of our study is presented in Figure 1. It consists of two flat panes of respective dimensions $1 \mathrm{~m} \times 0.45 \mathrm{~m}$ and $1 \mathrm{~m} \times$ $0.405 \mathrm{~m}$ and a plane absorber of the grey body type $\left(\varepsilon_{a b}=\right.$ $\left.\alpha_{a b}=0.95\right)$ dimension $1 \mathrm{~m} \times 0.405 \mathrm{~m}$, all assembled in a wooden box.

The principle of this modelling consists of writing the energy balance sheets of each component of the collector: transparent cover, heat transfer fluid, absorber, insulating materials.

\subsection{Energy Balance Equations}

\subsubsection{Hypothesis}

Temperatures of the upper and lower sides of the pane and absorber are considered to be equal and uniform.

The various thermal exchanges that take place, are shown schematically by the following equivalent electrical circuit in Figure 2.

with:

$$
\begin{gathered}
R_{1}=\frac{1}{h_{r . c 1-c i e l}} ; R_{2}=\frac{1}{h_{c v . c 1-v e n t}} ; R_{3}=\frac{1}{h_{c v . c 2-c 1}} ; R_{4}=\frac{1}{h_{r . c 2-c 1}} ; \\
R_{5}=\frac{1}{h_{c v . c 2-f}} ; R_{6}=\frac{1}{h_{c v . f-a b s}} ; R_{7}=\frac{1}{h_{r . a b s-c 2}} ; R_{8}=\frac{1}{U_{b}}
\end{gathered}
$$

The application of Ohm's law leads to the following equations:

\section{- First cover}

$$
\begin{aligned}
m_{c 1} & \frac{C_{P_{c 1}}}{S} \frac{\partial T_{c 1}}{\partial t}=G \cdot \alpha_{c 1}+h_{r . c 1 \_c i e l} \cdot\left(T_{a t}-T_{c 1}\right)+ \\
& h_{r . c 2 \_c 1} \cdot\left(T_{c 2}-T_{c 1}\right)+h_{v e n t} \cdot\left(T_{a m b}-T_{c 1}\right)+ \\
& h_{c v . c 1 \_c 2} \cdot\left(T_{c 2}-T_{c 1}\right)
\end{aligned}
$$




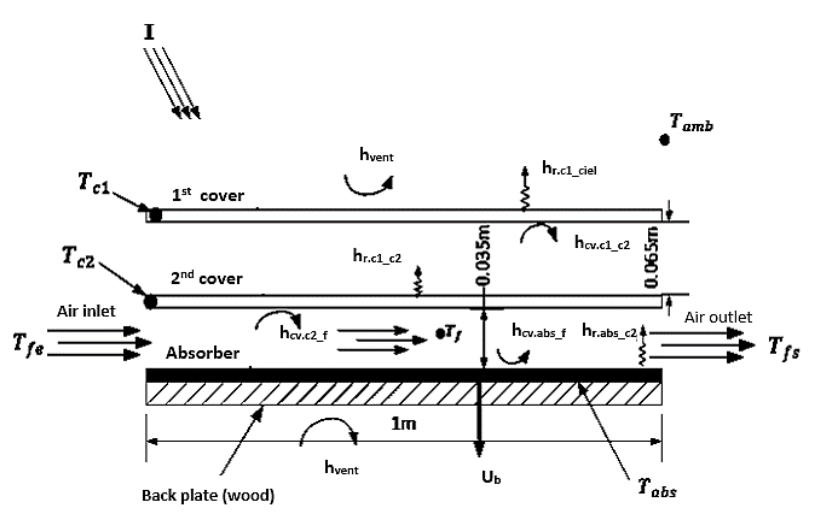

Figure 1. Schematic view of the solar collector doubleglazed air plane.

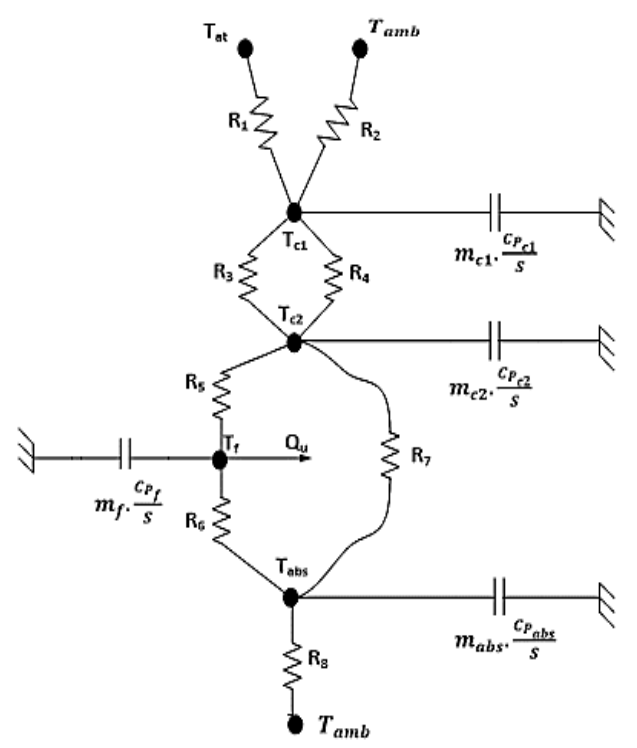

Figure 2. Equivalent electric model of the collector.

\section{- Second cover}

$$
\begin{aligned}
& m_{c 2} \cdot \frac{C_{P_{c 2}}}{S} \frac{\partial T_{c 2}}{\partial t}=G \cdot \alpha_{c 2} \cdot \tau_{c 1}+h_{r . c 2 \_c 1} \cdot\left(T_{c 1}-T_{c 2}\right) \\
& +h_{r . a b s s_{-} c 2} \cdot\left(T_{a b s}-T_{c 2}\right)+h_{c v . c 2_{-} f} \cdot\left(T_{f}-T_{c 2}\right) \\
& +h_{c v . c 1 \_c 2} \cdot\left(T_{c 1}-T_{c 2}\right)
\end{aligned}
$$

\section{- Fluid}

$$
\begin{gathered}
\rho_{f} e_{f} C_{P_{f}} \frac{\partial T_{f}}{\partial t}+\frac{\dot{m}_{f} \cdot C_{P_{f}}}{l} \frac{\partial T_{f}}{\partial x}=h_{c v . c 2_{-} f} \cdot\left(T_{c 2}-T_{f}\right) \\
+h_{c v . a b s_{-} f} \cdot\left(T_{a b s}-T_{f}\right)
\end{gathered}
$$

\section{Absorber}

$$
\begin{aligned}
m_{a b s} & \cdot \frac{C_{P_{a b s}}}{S} \frac{\partial T_{a b s}}{\partial t}=G \cdot \alpha_{a b s} \cdot \tau_{c 1, c 2}+h_{r . a b s_{-} c 2} \cdot\left(T_{c 2}-T_{a b s}\right) \\
& +h_{c v . a b s_{-} f} \cdot\left(T_{f}-T_{a b s}\right)+U_{b} \cdot\left(T_{a m b}-T_{a b s}\right)
\end{aligned}
$$

In practice, the time variations in the enthalpy of the collector components are small, meaning that the terms in m.C $C_{p} \cdot \frac{\partial T}{\partial t}$ can be neglected. .21 We can therefore reasonably assume that the collector is operating at a quasi-steady state. This hypothesis has the consequence of simplifying the equations without however masking the temporary evolution of the phenomena that remain related to the variable solar flux over time. In addition, we can overlook the solar absorptivity (visible and near IR) of the glazing. We thus have the following system:

$$
\begin{aligned}
0= & h_{r . c 1 \_c i e l} \cdot\left(T_{a t}-T_{c 1}\right)+h_{r \cdot c 2_{-} c 1} \cdot\left(T_{c 2}-T_{c 1}\right) \\
& +h_{v e n t} \cdot\left(T_{a m b}-T_{c 1}\right)+h_{c v \cdot c 1_{-} c 2} \cdot\left(T_{c 2}-T_{c 1}\right) \\
0= & h_{r . c 2_{-} c 1} \cdot\left(T_{c 1}-T_{c 2}\right)+h_{r \cdot a b s_{-} c 2} \cdot\left(T_{a b s}-T_{c 2}\right) \\
+ & h_{c v \cdot c 2_{-} f} \cdot\left(T_{f}-T_{c 2}\right)+h_{c v \cdot c 1_{-} c 2} \cdot\left(T_{c 1}-T_{c 2}\right) \\
& \frac{\dot{m}_{f} \cdot C_{P_{f}}}{l} \frac{d T_{f}}{d x}=h_{c v \cdot c 2_{-} f} \cdot\left(T_{c 2}-T_{f}\right) \\
& +h_{c v \cdot a b s_{-}} \cdot\left(T_{a b s}-T_{f}\right)
\end{aligned}
$$

$$
\begin{aligned}
0= & G \cdot \alpha_{a b s} \cdot \tau_{c 1, c 2}+h_{r . a b s_{-} c 2} \cdot\left(T_{c 2}-T_{a b s}\right) \\
& +h_{c v . a b s_{-} f} \cdot\left(T_{f}-T_{a b s}\right)+U_{b} \cdot\left(T_{a m b}-T_{a b s}\right)
\end{aligned}
$$

\subsubsection{Expression of Useful Power}

In order to study the distribution of temperature according to the direction of airflow, a fictitious $\delta \mathrm{x}$ slice is considered (see Figure 3). The temperature of the air is assumed to be uniform at the level of the section of the moving air seam of the collector.

Knowing that $l$ is the width of the collector, the conservation of energy in this slice gives us:

$$
\dot{m} C_{P} T_{f}+l \cdot \dot{Q}_{u} \cdot \delta x=\dot{m} C_{P}\left(T_{f}+\frac{d T_{f}}{d x} \delta x\right)
$$




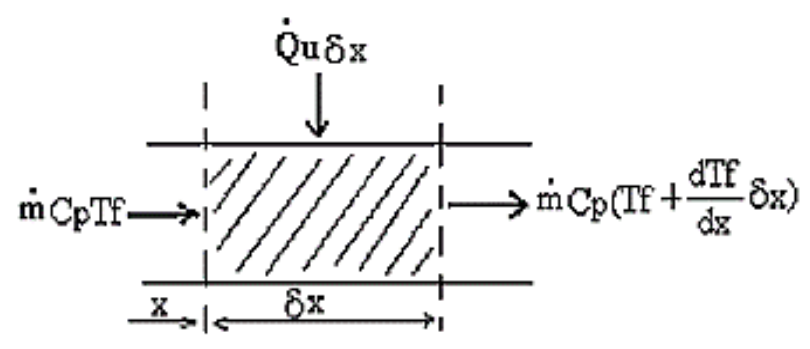

Figure 3. Thermal exchanges in a fictitious slice $\delta x$.

After simplification, we obtain:

$$
\frac{d T_{f}}{d x}=\frac{l \cdot \dot{Q}_{u}}{\dot{m} C_{P}}
$$

Generally, in the presence of a gaseous fluid such as air, we assume that the temperature of the $T_{f}$ fluid evolves uniformly throughout the fluid vein of the L-length collector Therefore the integration of the equation (above) is so trivial, we:

$$
T_{f}(x)=\frac{l \cdot \dot{Q}_{u}}{\dot{m} C_{P}} x+T_{f e}
$$

Where $T_{f e}$ is the inlet temperature of the fluid in the collector. The temperature $T_{f s}$ at the output of the collector is:

$$
T_{f s}=\frac{l \cdot \dot{Q}_{u}}{\dot{m} C_{P}} L+T_{f e}=\frac{S \cdot \dot{Q}_{u}}{\dot{m} C_{P}}+T_{f e}
$$

On the other hand, we also assume that the temperature of the fluid varies linearly throughout the collector; the average temperature value is therefore equal to the arithmetic mean between the input and the output:

$$
T_{f}=\frac{T_{f s}+T_{f e}}{2}
$$

From these relationships, and knowing that $S=l . L$ we can therefore write:

$$
\dot{Q}_{u}=\frac{2 \dot{m} C_{P}\left(T_{f}-T_{f e}\right)}{S}
$$

By replacing this expression in the equations of the Thermal balance and after simplifications, we end up with the following equation system:

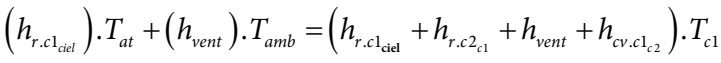

$$
\begin{aligned}
& -\left(h_{r . c 2 \_c 1}+h_{c v, c 1 \_c 2}\right) \cdot T_{c 2} \\
& 0=\left(h_{r . c_{c 1}}+h_{c v, c c_{c 2}}\right) \cdot T_{c 1}-\left(h_{r . c 2 \_c 1}+h_{c v, c 2_{-} c 1}+h_{r . a b s \_c 2}+h_{c v, c 2 \_f}\right) \cdot T_{c 2} \\
& +\left(h_{r . a b s \_c 2}\right) \cdot T_{a b s}+\left(h_{c v, c 2 \_f}\right) \cdot T_{f} \\
& \frac{2 \dot{m} C_{P}}{S} T_{f e}=\left(h_{c v . c 2 \_f}+h_{c v . a b s f}+\frac{2 \dot{m} C_{P}}{S}\right) \cdot T_{f} \\
& -\left(h_{c v . c 2_{-} \mathrm{f}}\right) \cdot T_{c 2}-\left(h_{c v . a b s \_f}\right) \cdot T_{a b s}
\end{aligned}
$$

$$
\begin{aligned}
& \text { G. } \alpha_{a b b} \cdot \tau_{c 1, c 2}+U_{b} \cdot T_{\text {amb }}=\left(h_{\text {r.abs_c2 }}+h_{\text {cv. abs_f } f}+U_{b}\right) \cdot T_{\text {abs }}- \\
& \left(\mathrm{h}_{\mathrm{r} . \text { abs_c2 } 2}\right) \cdot \mathrm{T}_{\mathrm{c} 2}-\left(\mathrm{h}_{\mathrm{cv}, \text { abs_f } \mathrm{f}}\right) \cdot \mathrm{T}_{\mathrm{f}}
\end{aligned}
$$

\subsection{Expression of Coefficients}

The radiative transfer coefficient between the transparent roofing system and the celestial vault is given by:

$$
\begin{gathered}
h_{r \cdot c-s k y}=\frac{1}{2} \cdot \sigma \cdot \varepsilon_{c} \cdot(1+\cos \cos \varphi) \cdot\left(T_{c}+T_{\text {ciel }}\right) \\
\cdot\left(T_{c}^{2}+T_{\text {ciel }}{ }^{2}\right)
\end{gathered}
$$

Where:

$T_{\text {sky: }}$ Equivalent temperature of the celestial vault given by the following Swinbank relationship 25 :

$$
T_{s k y}=0.0552 \times T_{a}^{1.5}
$$

The radiative exchange coefficient between the two panes is given by the following relation:

$$
h_{r . c 1-c 2}=\frac{\sigma\left(T_{c 1}+T_{c 2}\right) \cdot\left(T_{c 1}{ }^{2}+T_{c 2}{ }^{2}\right)}{\frac{1-\varepsilon_{c 1}}{\varepsilon_{c 1}}+\frac{1}{F_{c 1-c 2}}+\frac{1-\varepsilon_{c 2} S_{c 1}}{\varepsilon_{c 2} S_{c 2}}}
$$

The exchange coefficient between the pane and the absorber is given by the relation:

$$
h_{r . c 2-a b s}=\frac{\sigma\left(T_{c 2}+T_{a b s}\right) \cdot\left(T_{c 2}{ }^{2}+T_{a b s}{ }^{2}\right)}{\frac{1-\varepsilon_{c 2}}{\varepsilon_{c 2}}+\frac{1}{F_{c 2-a b s}}+\frac{1-\varepsilon_{a b s} S_{c 2}}{\varepsilon_{a b s} S_{a b s}}}
$$

The convective exchange coefficient between the ambient air and the pane is given by the empirical correlation of Hottel and Woert $z^{26}$ :

$$
h_{c v . c 1-v e n t}=h_{\text {Vent }}=5.7+3.8 \times V_{\text {vent }}
$$


The convective transfer coefficient between the two panes is given by:

$$
h_{c v . c 1-c 2}=\frac{N_{u} \times \lambda_{a}}{D_{h}}
$$

In which the number of Nusselt is given by:

$$
\begin{aligned}
N_{u}= & +1.44\left[1-\frac{1708 \cdot(\sin 1 \cdot 8 \varphi)^{1.6}}{R_{a} \cdot \cos \varphi}\right]\left[1-\frac{1708}{R_{a} \cdot \cos \varphi}\right] \\
& +\left[\left(\frac{R_{a} \cdot \cos \varphi}{5830}\right)^{1 / 3}-1\right]
\end{aligned}
$$

The convective exchange coefficient in the moving air is given by:

$$
h_{c v . c 2 \_f}=h_{c v . a b s \_f}=\frac{N_{u} \times \lambda_{f}}{D_{h}}
$$

The Nusselt number is usually according to the flow regime, set by the Reynolds:

$$
R_{e}=\frac{\dot{m}_{f} \times D_{h}}{S_{f} \times \mu} \text { with } D_{h}=\frac{2 \times l \times H_{h}}{l+H_{h}}
$$

- In Laminar flow $\left(R_{e}<2100\right)$ the Nusselt number is described by the Mercer correlation $\underline{27}$ :

$$
N_{u}=4.9+\frac{0.0606 \times\left(\frac{R_{e} \cdot P_{r} \cdot D_{h}}{L}\right)^{1.2}}{1+0.0909 \times\left(\frac{R_{e} \cdot P_{r} \cdot D_{h}}{L}\right)^{0.7} P_{r}^{0.17}}
$$

- In Turbulent flow $\left(R_{e}<2100\right)$ the Nusselt number is described by the Kays correlation $\underline{27}$ :

$$
\mathrm{N}_{\mathrm{u}}=0.0158 \times \mathrm{R}_{\mathrm{e}}^{0.8}
$$

\section{Greenhouse Effect Modelling in the Collector}

Radiation from the collector's cover reaches the absorber directly or indirectly after an arbitrary number of reflections and/or transmissions through the glass surface and reflections by the absorber. Our objective is to take into account this multitude of radiation paths. Work has been carried out in this direction, $, 23,24$ but within the framework of an agricultural greenhouse, assuming throughout its work that the exchange of radiation takes place between completely diffusive surfaces, that is to say, that all the radiation emitted, reflected or transmitted has uniform intensity in all angular directions. As regards to thermal radiation, we know that it is emitted isotropically by the radiant surface: this assumption is therefore valid in this case.

\subsection{Concept of Multiple Reflections}

The useful profile of a double-glazed plane collector can be assimilated into three parallel flat surfaces. What interests us is the radiation exchange between the first plane $\left(S_{1}\right)$, the second plane $\left(\boldsymbol{S}_{2}\right)$ and the absorber $\left(\boldsymbol{S}_{3}\right)$ as shown in Figure 4 . The rays can take multitude paths.

In the particular case where $S_{3}$ is a diffuse emission grey surface, the amount of radiation actually absorbed may be determined $\underline{28,29}$ :

$$
G_{a b s}=I \cdot \alpha_{3} \cdot \tau_{1,2} \cdot\left(1+\rho_{1,2} \cdot \rho_{3}+\rho_{1,2}{ }^{2} \cdot \rho_{3}{ }^{2}+\ldots+\rho_{1,2}{ }^{n} \cdot \rho_{3}{ }^{n}\right)
$$

with :

$$
\begin{gathered}
\tau_{1,2}=\tau_{1} \cdot \tau_{2} \cdot\left(1+\rho_{1} \cdot \rho_{2}+\rho_{1}^{2} \cdot \rho_{2}^{2}+\ldots+\rho_{1}^{n} \cdot \rho_{2}^{n}\right) \\
=\tau_{1} \cdot \tau_{2} \cdot \frac{1}{1-\rho_{1} \cdot \rho_{2}}=\tau_{1} \cdot \tau_{2} \cdot K_{1} \\
\rho_{1,2}=\frac{\left(\rho_{1}+\rho_{2}-2 \cdot \rho_{1} \cdot \rho_{2}\right)}{\left(1-\rho_{1} \cdot \rho_{2}\right)}
\end{gathered}
$$

The factor materialising the phenomenon of multiple reflections is given by:

$$
\begin{aligned}
& \tau_{1,2} \cdot\left(1+\rho_{1,2} \cdot \rho_{3}+\rho_{1,2}{ }^{2} \cdot \rho_{3}{ }^{2}+\ldots+\rho_{1,2}{ }^{n} \cdot \rho_{3}{ }^{n}\right) \\
& =\frac{\tau_{1,2}}{1-\rho_{1,2} \cdot \rho_{3}}=\frac{\tau_{1} \cdot \tau_{2} \cdot K_{1}}{1-\rho_{1,2} \cdot \rho_{3}}=\tau_{1} \tau_{2} \cdot K
\end{aligned}
$$

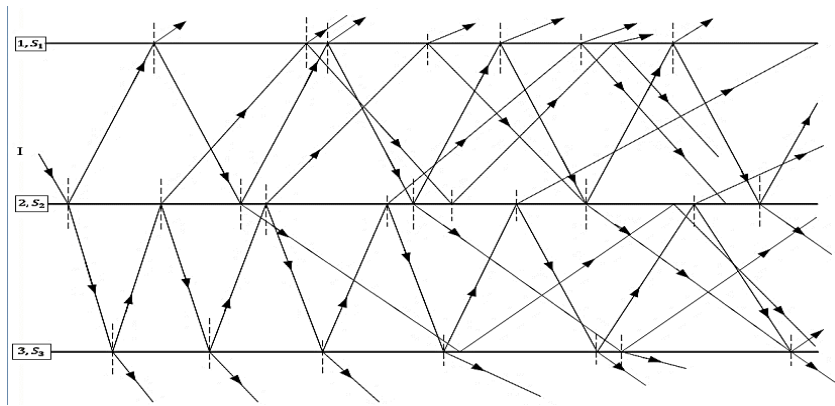

Figure 4. Potential pathways of radiation in the doubleglazed plane collector. 


$$
K=\frac{1}{\left[1-\rho_{1} \cdot \rho_{2}-\rho_{3} \cdot\left(\rho_{1}+\rho_{2}-2 \rho_{1} \cdot \rho_{2}\right)\right]}
$$

\subsection{Net Infrared Radiation Absorbed by the Collector}

\subsubsection{Different fluxes in contribution}

$T_{n}$ is the absolute temperature of the surface $n$. Its emissive power, that is the rate of energy emitted per unit of surface, is given by the Stefan-Boltzmann law:

$$
\varnothing=\varepsilon_{n} \cdot \sigma \cdot T_{n}^{4}
$$

\section{- Flux emitted by the atmosphere}

Flux density descending from atmospheric radiation $\varnothing_{a t} \downarrow$ reaching the absorber is given by:

$$
\mathrm{S}_{\mathrm{ab}} \cdot \varnothing_{\mathrm{at}} \downarrow=\mathrm{X} \cdot \varepsilon_{\mathrm{at}} \cdot \sigma \cdot \mathrm{T}_{\mathrm{at}}{ }^{4} \cdot \mathrm{S}_{\mathrm{at}}
$$

It involves the factor $\boldsymbol{\varepsilon}_{a t}$ which represents the infrared emittance of the sky, known to be somewhere between 0.72 (clear sky) and 1 (overcast sky).

$\mathrm{X}$ takes into account collector configuration (angle factor, roofing transmission coefficients) and multiple reflections.

\section{- Flux emitted by the transparent cover}

Flux density descending from the thermal radiation emitted by the transparent cover $\varnothing_{c} \downarrow$ which reaches the absorber is given by:

$$
S_{a b} \cdot \varnothing_{c} \downarrow=Z \cdot \varepsilon_{c} \cdot \sigma \cdot T_{c}^{4} \cdot S_{c}
$$

$\mathrm{Z}$ takes into account the collector's configuration (angle factor, roofing transmission coefficients) and multiple reflections.

\section{- Flux emitted by the absorber}

The radiation emitted by the absorber also gives rise to a descending flux density $\varnothing_{a b} \downarrow$. It includes two contributions: the flux density of radiation emitted by the absorber which after reflection at first contact with the cover, is finally returned, and the corresponding flux density which is transmitted during its first contact with the cover but which is finally returned after a certain number of exchanges in different parts of the cover, while taking into account the multiple reflections.

$$
S_{a b} \cdot \varnothing_{a b} \downarrow=W \cdot \varepsilon_{a b} \cdot \sigma \cdot T_{a b}{ }^{4} \cdot S_{a b}
$$

$\mathrm{W}$ takes into account the collector's configuration (angle factor, roofing transmission coefficients) and multiple reflections.

\subsubsection{Absorbed Infrared Radiation}

$$
I R=\alpha_{\mathrm{ab}} \times\left[\varnothing_{\mathrm{c}} \downarrow+\varnothing_{\mathrm{at}} \downarrow+\varnothing_{\mathrm{ab}} \downarrow\right]
$$

\subsection{Loss of IR Radiation to Absorber}

\subsubsection{Different Ascending Flux}

The ascending thermal radiation flux has the following flux densities:

$$
\begin{gathered}
\varnothing_{c} \uparrow=\rho_{a b} . \varnothing_{c} \downarrow \\
\varnothing_{a t} \uparrow=\rho_{a b} . \varnothing_{a t} \downarrow \\
\varnothing_{a b} \uparrow=\varepsilon_{a b} \cdot \sigma \cdot T_{a b}^{4} \cdot K
\end{gathered}
$$

\subsubsection{Radiation Losses to Absorbers}

$$
R=\varnothing_{c} \downarrow+\varnothing_{a t} \downarrow+\varnothing_{a b} \downarrow-\varnothing_{c} \uparrow-\varnothing_{a t} \uparrow-\varnothing_{a b} \uparrow
$$

\section{Results and Discussion}

The theoretical solar irradiance calculated for the sunniest day of April is shown in Figure 5.

Consistent with all forecasts, the curve looks like a bell. This explains the increase and decrease in the sunshine, respectively during the day and in the afternoon. From 6:00 am the irradiance is at $33.15 \mathrm{~W} \cdot \mathrm{m}^{-2}$ and gradually increases to reach a maximum value of $1032.59 \mathrm{~W} / \mathrm{m}^{2}$ at 12:00 am and then it decreases to $33.15 \mathrm{~W} . \mathrm{m}^{-2}$ at $6: 00 \mathrm{pm}$. These results are consistent with those of the literature.

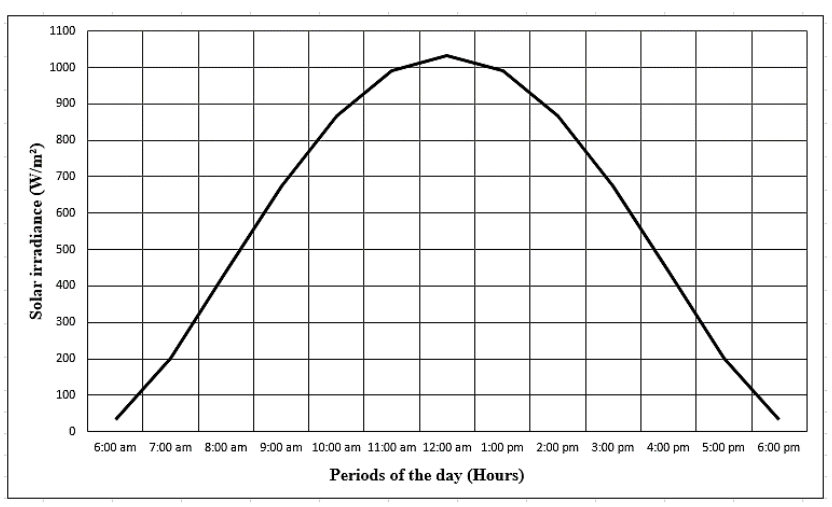

Figure 5. Evolution of the average daily irradiance according to day time. 
Figure 6 shows the variation in parameters characterizing the apparent motion of the sun in Ngaoundéré.

Analysis of the curves shows that the solar noon ranges from $83.68^{\circ}$ to $89.99^{\circ}$ for the entire month. These heights are reached at $12.00 \mathrm{pm}$ of the day and the sunshine is maximum at this time. The widest angle corresponds to the 12th day of the month. The declination varies on average by $0.36^{\circ}$ per day. The minimum and maximum declination values are $2.98^{\circ}$ and $13.69^{\circ}$ respectively. These results relate to the geographical coordinates of Ngaoundéré (latitude $7.33^{\circ} \mathrm{N}$, longitude $58.58^{\circ} \mathrm{E}$, altitude $1205 \mathrm{~m}$ ) and the motion of the Earth.

The temperature curves (glazing, atmosphere and absorber) of the collector are shown in Figure 7.

Maximum temperatures are observed around 12:00 PM (local time). This evolution is quite normal in view of the evolution of the density of solar flux in the same period of the day. The temperature of the absorber is naturally the highest and its maximum value revolves

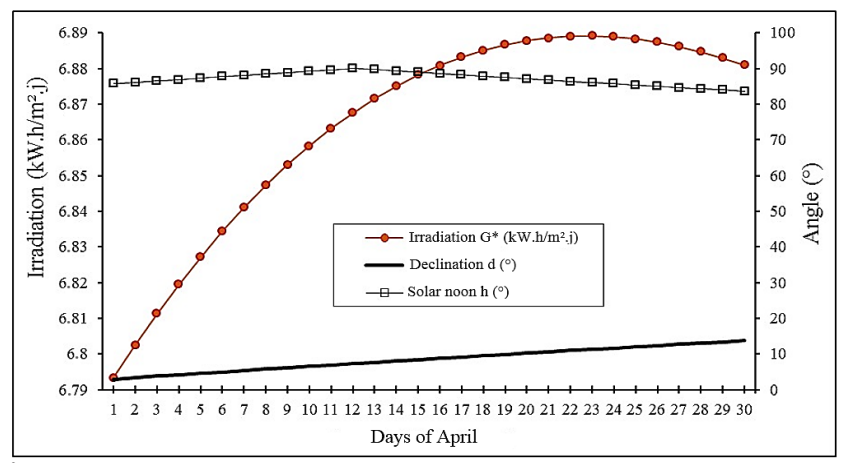

Figure 6. Variation of irradiation, declination and solar noon according to the days of April.

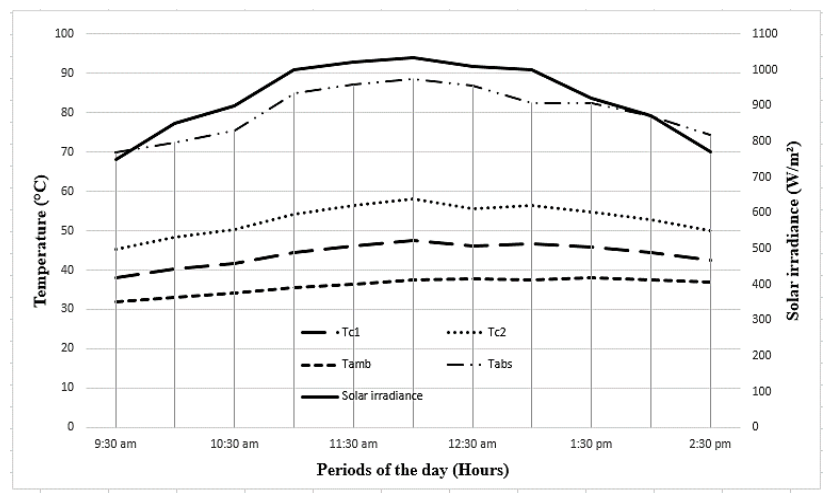

Figure 7. Temperature curves of the double-glazed plane collector elements. around $88^{\circ} \mathrm{C}$. These results are entirely consistent with those of the literature.

Absorbed Infrared radiation takes into account the following different fluxes:

\subsection{First Cover}

$$
S_{a b} \cdot \oslash_{c 1} \downarrow=\varepsilon_{c 1} \cdot \sigma \cdot T_{c 1}^{4} \cdot S_{c 1} \cdot F_{c 1, c 2} \cdot \tau_{c 2} \cdot F_{c 2, a b} \cdot K
$$

Knowing that $F_{c 2, c 1} \cdot S_{c 2}=F_{c 1, c 2} \cdot S_{c 1}$; and $F_{c 2, a b} \cdot S_{c 2}=F_{a b, c 2} \cdot S_{a b}$ and $F_{c 2, a b} \cdot S_{c 2}=F_{a b, c 2} \cdot S_{a b}$

We obtain

$$
\varnothing_{c 1} \downarrow=K \cdot \tau_{c 2} \cdot F_{c 2, c 1} \cdot \varepsilon_{c 1} \cdot \sigma \cdot T_{c 1}^{4}
$$

\subsection{Second Cover}

$$
\begin{aligned}
& S_{a b} \cdot \varnothing_{c 2} \downarrow=\varepsilon_{c 2} \cdot \sigma \cdot T_{c 2}{ }^{4} \cdot S_{c 2} \cdot \\
& \left(F_{c 2, a b}+F_{c 2, c 1} \cdot \rho_{c 1} \cdot F_{c 1, c 2} \cdot \tau_{c 2} \cdot F_{c 2, a b}\right) \cdot K
\end{aligned}
$$

Knowing that $F_{c 2, a b} \cdot S_{c 2}=F_{a b, c 2} \cdot S_{a b}$

We obtain

$$
\varnothing_{c 2} \downarrow=K \cdot F_{a b, c 2} \cdot\left(1+F_{c 2, c 1} \cdot \rho_{c 1} \cdot F_{c 1, c 2} \cdot \tau_{c 2}\right) \cdot \varepsilon_{c 2} \cdot \sigma \cdot T_{c 2}{ }^{4}
$$

\subsection{Atmosphere}

$$
S_{a b} \cdot \varnothing_{a t} \downarrow=\varepsilon_{a t} \cdot \sigma \cdot T_{a t}^{4} \cdot S_{a t} \cdot F_{a t, c 1} \cdot \tau_{c 1} \cdot \tau_{c 2} \cdot F_{c 2, a b} \cdot K
$$

Knowing that: $F_{c 1, a t} \cdot S_{c 1}=F_{a t, c 1} \cdot S_{a t}$ the equation becomes:

$$
\varnothing_{a t} \downarrow=\varepsilon_{a t} \cdot \sigma \cdot T_{a t}^{4} \cdot F_{c 1, a t} \cdot \frac{S_{c 1}}{S_{a b}} \cdot \tau_{c 1} \cdot \tau_{c 2} \cdot F_{c 2, a b} \cdot K
$$

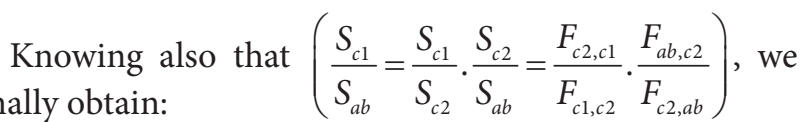

$$
\varnothing_{a t} \downarrow=K \cdot F_{c 1, a t} \cdot F_{a b, c 2} \cdot \frac{F_{c 2, c 1}}{F_{c 1, c 2}} \cdot \tau_{c 1} \cdot \tau_{c 2} \cdot \varepsilon_{a t} \cdot \sigma \cdot T_{a t}{ }^{4}
$$

\subsection{Absorber}

$$
\begin{aligned}
& S_{a b} \cdot \varnothing_{a b} \downarrow=\varepsilon_{a b} \cdot \sigma \cdot T_{a b}^{4} \cdot S_{a b} \cdot F_{a b, c 2} \\
& \quad .\left(\rho_{c 2} \cdot F_{c 2, a b}+\tau_{c 2} \cdot F_{c 2, c 1} \cdot \rho_{c 1} \cdot F_{c 1, c 2} \cdot F_{c 2, a b}\right) \cdot \mathrm{K}
\end{aligned}
$$

Taking into consideration that in this plane collector, $F_{a b, c 2}=F_{c 2, a b}=F_{c 1, c 2}=F_{c 2, c 1}=1$, the amount of Infrared radiation absorbed is given by the equation below: 


$$
\begin{aligned}
I R= & \alpha_{a b s} \cdot K \cdot\left[A \cdot \varepsilon_{c 1} \cdot \sigma \cdot T_{c 1}{ }^{4}+D \cdot \varepsilon_{c 2} \cdot \sigma \cdot T_{c 2}{ }^{4}\right. \\
& \left.+B \cdot F_{c 1, a t} \cdot \varepsilon_{a t} \cdot \sigma \cdot T_{a t}{ }^{4}+C \cdot \varepsilon_{a b} \cdot \sigma \cdot T_{a b}{ }^{4}\right]
\end{aligned}
$$

with:

$$
A=\tau_{c 2} ; D=\left(1+\rho_{c 1} \cdot \tau_{c 2}\right) ; B=\tau_{c 1} \cdot \tau_{c 2} ; C=\left(\rho_{c 2}+\rho_{c 1} \cdot \tau_{c 2}^{2}\right) \quad C=\left(\rho_{c 2}+\rho_{c 1} \cdot \tau_{c 2}^{2}\right)
$$

The graph of this equation giving the infrared radiation absorbed by the collector is shown in Figure 8 .

The shape of this curve is justified by the solar flux density profile. Maximum absorbed IR radiation is observed at around 12:00 am (local time) and its value is around $678 \mathrm{~W} / \mathrm{m}^{2}$. This value is related to the optical properties of the collector elements and may therefore be different from that obtained with another collector. However, the order of magnitude is consistent with the values found in the literature.

Radiation losses to the absorber are given by the equation below

$$
\begin{aligned}
R= & K \cdot\left[A \cdot\left(1-\rho_{a b}\right) \cdot \varepsilon_{c 1} \cdot \sigma \cdot T_{c 1}{ }^{4}+D \cdot\left(1-\rho_{a b}\right) \cdot \varepsilon_{c 2} \cdot \sigma \cdot T_{c 2}{ }^{4}\right. \\
& \left.+B \cdot\left(1-\rho_{a b}\right) \cdot F_{c 1, a t} \cdot \varepsilon_{a t} \cdot \sigma \cdot T_{a t}{ }^{4}+C^{*} \cdot \varepsilon_{a b} \cdot \sigma \cdot T_{a b}{ }^{4}\right]
\end{aligned}
$$

With:

$$
C^{*}=\left[\left(\rho_{c 2}+\rho_{c 1} \cdot \tau_{c 2}^{2}\right)-1\right]
$$

The graph of this equation giving infrared radiation losses to the absorber is shown in Figure 9.

The radiation loss curve looks like a bathtub where the lowest peak is observed at 12:30 pm (local time). This can be explained by the inertia of the absorber material. The analysis of this curve also shows that the maximum value of radiation losses (the difference between the amount of IR that arrives and the amount that leaves the absorber) is $250 \mathrm{~W} / \mathrm{m}^{2}$.

AQ2

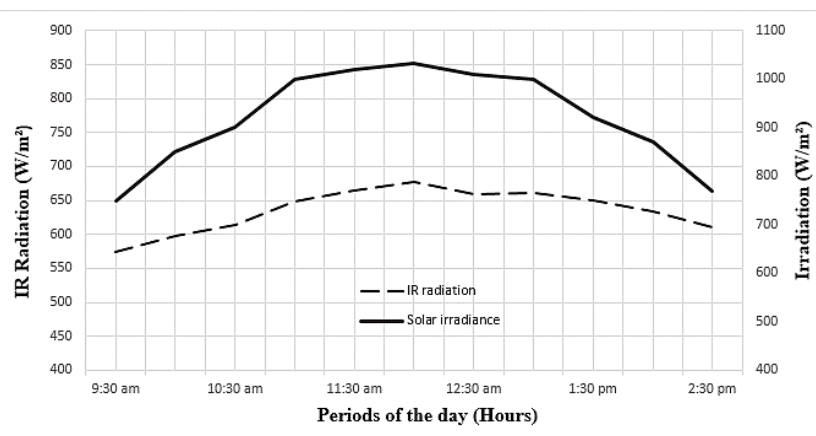

Figure 8. Infrared radiation absorbed by the collector.

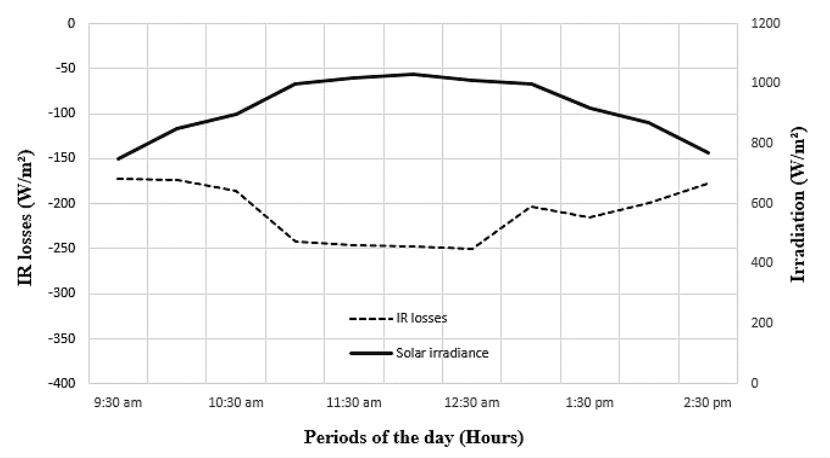

Figure 9. Infrared radiation loss to absorber.

\section{Conclusion}

We have developed a mathematical model to compute the net absorbed infrared radiation as well as the radiation losses at the level of the absorber of a double-glazed plane collector. A characterization of the environment in natural sunshine of the city of Ngaoundéré Cameroon allowed to visualize graphically the profiles obtained from established mathematical relationships, and the results showed that the maximum temperatures of the collector elements, as well as the maximum value of the absorbed net radiation, are reached at solar noon, the moment when the sun is maximum in this locality. On the other hand, due to the inertia of the absorber, the maximum value of losses is observed 30 minutes after. The greenhouse effect in the collector greatly affects its performance. We have highlighted its close relationship with the optical and radiometric properties of the collector as well as the ambient conditions in which the collector is located; this can give us a clear idea of the influence of the collector parameters (number of covers, optical and radiometric properties) on its performance.

\section{References}

1. Perrot T. Rapport sur la situation actuelle de la conversion énergetique directe de l'énergie solaire et aperçus futurs, Adv Energy Convers. 1965;5(4):241-64.

2. Mokhtari F, Semmar D. L'influence de la configuration de l'absorbeur sur les performances thermiques d'un capteur solaire à air, Revue des Energies Renouvelables. 2001: 159-162.

3. Choudhury C, Garg PH. Evaluation of a jet plate air heater. Solar Energy. 1991;46(4):199-209.

4. Semmar D, Betrouni S, Lafri D. Etude et Réalisation d'un Capteur Solaire à Air. Revue des Energies Renouvelables: Physique Energétique. 1998:33-8. 
5. Abene A, Dubois V, Ouaged A, Si-Youcef M, Leray M. Etude expérimentale de capteurs solaires à air: Le séchage de la Figue. Technologies Avancées. 2005;17:15-28.

6. Karim MA, Hawlader MNA. Performance evaluation of a v-groove solar air collector for drying applications. Appl Therm Eng. 2006;26(1):121-30.

7. Karim MA, Hawlader MNA. Performance investigation of flat plate, v-corrugated and finned air collectors. Energy. 2006;31:452-70.

8. Labed A, Moummi N, Benchabane A, Aoues K, Zellouf M. Performances thermiques et pertes decharges de différentes configurations de capteurs solaires plans à air Etude expérimentale dans la région de Biskra, Algérie. Revue des Energies Renouvelables. 2015;18(2):209-16.

9. Ahmed-Zaid A, Messaoudi H, Abenne A, Leray M, Desmons JY, Abed B. Experimental study of thermal performance improvement of a solar air flat plate collector through the use of obstacles: application for the drying of 'yellow onion'. Int J Energy Resh. 1999;23(12):1083-99.

10. Youcef-Ali S. Study and optimization of the thermal performances of the offset rectangular plate fin absorber plates, withvarious glazing. Renew Energy. 2005;30(2):271-80.

11. Turhan K. Performance of various design of solar air heatersfor crop drying applications', Renew Energy. 2006;31(7):1073-88.

12. Romdhane BS. The air solar collectors: Comparative study, introduction of baffles to favor the heat transfer. Sol Energy. 2007;81:139-49.

13. Aoues K, Moummi N, Moummi A, Zellouf M, Labed A, Achouri E. Etude de l'influence des rugosités artificielles sur les performances thermiques des capteurs solaires plans à air. Revue des Energies Renouvelables. 2008;11(2):219-27.

14. Mohamad AA. High Efficiency solar air heater. Sol Energy. 1997;60(2):71-6.

15. Ekechukwu OV, Norton B. Review of solar-energy drying systems III: low temperature air-heating solar collectors for crop drying applications. Energy Convers Manag. 1999;40:657-67.
16. Ahmed-Zaïd A, Moulla A, Hantala MS, Desmons JY. Amélioration des Performances des capteurs solaires plans à air : Application au séchage de l'oignon jaune et du Hareng. Revue des Énergies Renouvelables. 2001;4:69-78.

17. Benkhelifa A. Optimisation d'un capteur solaire plan. Revue des Energies Renouvelables. 1998:13-8.

18. Hachemi A. Experimental study of thermal performance of offset rectangular plate fin absorber-plates. Renew Energy. 1999; 17:371-84.

19. Oudjedi S, Boubghal A, Braham CW, Chergui T, Belhamri A. Etude paramétrique d'un capteur solaire plan à air destiné au séchage (Partie: 2). Revue des Energies Renouvelables. 2008:255-66.

20. Tchinda R. A review of the mathematical models for predicting solar air heaters systems. Renew Sustain Energy Rev. 2009;13:1734-59.

21. Giovannetti F, Föste S, Ehrmann N, Rockendorf G. High transmittance, low emissivity glass covers for flat plate collectors: applications and performance. Energy Procedia. 2012;30:106-15.

22. Karim MA, Perez E, Amin ZM. Mathematical modelling of counter flow v-grove solar air collector. Renew Energy. 2014;67:192-201.

23. Ana MS, Rosa R. Radiative heat loss inside a greenhouse. J Agric Eng Res. 1987;37(3-4):155-62.

24. Rosa R. Solar and thermal radiation inside a multispan greenhouse. J Agric Eng Res. 1988;40(4):285-95.

25. Swinbank WC. Long-wave radiation from clear skies. Q J Royal Meteorol Soc. 1963;89(381):339-48.

26. Hottel HC, Woertz BB. The performance of flat-plate solar heat collectors. Trans of ASME. 1942;64:98.

27. Njomo D. Etude théorique du comportement thermique d'un capteur solaire plan à air à couverture combinée plastiquevitre. Revue Générale de Thermique. 1998;37:973-80.

28. Jaffrin A, Makhlouf S. Mechanism of light transmission through wet polymer films. Acta Horticult. 1990;281:11-24.

29. Chaibi MT, Jilar T. Effects of a solar desalination Module integrated in a greenhouse roof on light transmission and crop growth. Biosyst Eng. 2005;90(3):319-30. 